\title{
BMJ Open Mismatch between antenatal care attendance and institutional delivery in south Ethiopia: A multilevel analysis
}

\author{
Anteneh Asefa, ${ }^{\oplus 1,2}$ Samson Gebremedhin, ${ }^{\circledR 1}$ Tamiru Messele, ${ }^{3}$ Yohannes Letamo, ${ }^{3}$ \\ Endashaw Shibru, ${ }^{3}$ Abraham Alano, ${ }^{3}$ Alison Morgan, ${ }^{2}$ Michelle Kermode ${ }^{2}$
}

To cite: Asefa A,

Gebremedhin S, Messele T, et al. Mismatch between antenatal care attendance and institutional delivery in south Ethiopia: A multilevel analysis. BMJ Open 2019;9:e024783. doi:10.1136/ bmjopen-2018-024783

- Prepublication history for this paper is available online. To view these files, please visit the journal online (http://dx.doi org/10.1136/bmjopen-2018024783).

Received 21 June 2018 Revised 24 December 2018 Accepted 1 February 2019

Check for updates

(C) Author(s) (or their employer(s)) 2019. Re-use permitted under CC BY-NC. No commercial re-use. See rights and permissions. Published by BMJ.

${ }^{1}$ School of Public Health, College of Medicine and Health Sciences, Hawassa University, Hawassa, Ethiopia

${ }^{2}$ Nossal Institute for Global Health, School of Population and Global Health, University of Melbourne, Melbourne, Victoria, Australia

${ }^{3}$ Southern Nations Nationalities and Peoples Region Health Bureau, Hawassa, Ethiopia

Correspondence to

Anteneh Asefa;

antex98@yahoo.com

\section{ABSTRACT}

Objectives Uptake of maternal health services remains suboptimal in Ethiopia. Significant proportions of antenatal care attendees give birth at home. This study was conducted to identify the predictors of non-institutional delivery among women who received antenatal care in the Southern Nations Nationalities and Peoples Region, Ethiopia.

Design A community-based cross-sectional survey was conducted among women who delivered in the year preceding the survey and who had at least one antenatal visit. Multistage cluster sampling was deployed to select 2390 women from all administrative zones of the region. A mixed-effects multivariable logistic regression analysis was performed to assess the predictors of non-institutional delivery; adjusted ORs (AOR) with 95\% Cls are reported. Results The proportion of non-institutional deliveries among participants was $62.2 \%$ (95\% Cl $60.2 \%$ to $64.2 \%)$. Previous experience of short and simple labour (46.9\%) and uncomplicated home birth (42.9\%), night-time labour (29.7\%), absence of pregnancy-related problem (18.8\%) and perceived providers poor reception of women (17.8\%) were the main reasons to have non-institutional delivery. Attending secondary school and above $(\mathrm{AOR}=0.51 ; 95 \% \mathrm{Cl}$ 0.30 to 0.85 ), being a government employee ( $\mathrm{AOR}=0.27$; $95 \% \mathrm{Cl} 0.10$ to 0.78 ) and woman's autonomy in healthcare utilisation decision making $(\mathrm{AOR}=0.51 ; 95 \% \mathrm{Cl} 0.33$ to 0.79 ) were among the independent predictors negatively associated with non-institutional delivery. On the other hand, unplanned pregnancy $(\mathrm{AOR}=1.67 ; 95 \% \mathrm{Cl}$ 1.16 to 2.42), not experiencing any health problem during pregnancy ( $\mathrm{AOR}=8.1 ; 95 \% \mathrm{Cl} 3.12$ to 24.62), not perceiving the risks associated with home delivery ( $\mathrm{AOR}=6.64 ; 95 \% \mathrm{Cl} 4.35$ to 10.14) were the independent predictors positively associated with non-institutional delivery.

Conclusions There is a missed opportunity among women attending antenatal care in southern Ethiopia. Further health system innovations that help to bridge the gap between antenatal care attendance and institutional delivery are highly recommended.

\section{INTRODUCTION}

Regardless of significant reduction in global maternal mortality, low-income and middle-income countries (LMICs) still remain home to almost all (99\%) global

\section{Strengths and limitations of this study}

- The study covered all administrative levels in Southern Nations Nationalities and Peoples Region, which are home to 56 nations and nationalities and thus accounted for possible cultural diversities and variations in residential settings (urban, rural agrarian and rural pastoralist).

- The multistage cluster sampling and the multilevel analysis deployed helped to minimise clustering of the outcome variable (place of delivery).

- This study would have benefited more from exploration of women's experiences of antenatal care that are believed to highly influence their decision on place of delivery.

maternal mortality; $66 \%$ of the global maternal mortality happened in the sub-Saharan African region only, in 2015. ${ }^{1}$ Ethiopia $(3.6 \%)$ together with Nigeria $(19 \%)$, India $(15 \%)$, Democratic Republic of the Congo $(7.3 \%)$ and Pakistan $(3.2 \%)$ collectively contribute to $48 \%$ of global maternal mortality. ${ }^{1}$ The 2016 Ethiopian Demographic and Health Survey revealed that the maternal mortality ratio in the country was 412 per 100000 live births, a $52.7 \%$ reduction from its level in the year 2000 (817 per 100000 live births). In 2015, maternal deaths accounted for $25 \%$ of all deaths among women aged 15-49 years in the country. ${ }^{2}$ Women's (dis) empowerment, poverty, lack of education, poor access to and utilisation of reproductive and maternal health services and demographic features such as early marriage are among the constellation of factors that accelerate maternal mortality. ${ }^{3}$

Although there is strong evidence that most maternal deaths happen during the time of childbirth or during the 24 hours following childbirth, access to and utilisation of life saving maternal health services remains inadequate in LMICs. Cultural beliefs and practices, impoverishment, weak governance, 
limited and low-quality health infrastructure, conflicts, disasters and inequities are factors that impede access to and utilisation of maternal health services in the sub-Saharan Africa. ${ }^{45}$ In Ethiopia, the proportion of pregnant women who have at least one antenatal care visit increased from $27 \%$ to $67.4 \%$ between 2000 and 2015 . In the same period, the proportion of institutional delivery increased from $5 \%$ to $26 \%{ }^{2}$ This suggests a missed opportunity in the continuum of care provided to women of reproductive age. A study conducted in northwest Ethiopia in 2012 revealed that antenatal care utilisation had a limited role in health facility reattendance for skilled delivery services. ${ }^{6}$

In Ethiopia, perceived poor quality of care, ${ }^{78}$ previous bad experiences of health facility-based delivery, ${ }^{9}$ long distance, ${ }^{610}$ costs associated with facility-based delivery ${ }^{11}$ and pressure from elders in the communities ${ }^{12}$ are among the most frequently cited reasons for having non-institutional delivery. In addition, poor health providers' behaviour and attitudes towards women, these days termed as mistreatment, also contribute to a preference for home delivery in Ethiopia. ${ }^{12}$

There is an evidence gap on why the majority of Ethiopian women who receive antenatal care do not reattend health facilities for skilled delivery care. Therefore, a community-based study was conducted to identify factors associated with non-institutional delivery among women who attended at least one antenatal visit. The study included women from all administrative catchments of the Southern Nations Nationalities and Peoples Region (SNNPR) to account for the cultural diversity, which is believed to affect place of delivery. ${ }^{14}$ Accordingly, this study adds to existing limited evidence that can inform the design of strategies that aim to retain antenatal care attendees in the continuum of care.

\section{MATERIALS AND METHODS \\ Study setting}

This study was conducted in the SNNPR, Ethiopia that is home to 56 nations and nationalities (ethnic groups) with different languages and cultural heritage. The capital city of the region is Hawassa. The total population size of the region was estimated to be 16738177 in 2012 of which $49.7 \%$ were males while the remaining were females; women of reproductive age group account for $23.3 \%$ of the general population and $3.9 \%$ of them bear a child each year. The region had 324 urban and 3602 rural (where close to $90 \%$ of the population live) administrative kebeles, the lower administration levels in Ethiopia comprising about 1000 households. During the survey period, 1 specialised teaching hospital, 1 referral hospital, 8 general hospitals, 9 primary hospitals, 513 health centres, and 3498 health posts were available in the region. In the current study, all 14 administrative zones, 1 city administration (Hawassa city), and 4 special districts of the SNNPR were included. In SNNPR, there are a total of 164 districts (locally called woredas). The four special districts and the city administration are standalone administrative subregions that are accountable to the regional government and are treated as equivalent to an administrative zone. The remaining districts are accountable to the administrative zones. Administrative zones have a higher proportion of their population from one ethnic group, although they are home to more than one ethnic groups. Similarly, districts and kebeles are typically populated with a higher proportion of similar ethnic groups, although more than one ethnic group may belong to them.

\section{Study design}

A community-based cross-sectional survey was conducted in January 2013. A structured and pretested questionnaire was administered to assess why women who attend antenatal clinics do not deliver in health institutions.

\section{Study participants and eligibility}

Women who had at least one birth in the 1 year preceding the survey period and who had received at least one antenatal care assessment from a skilled provider were invited to participate in the study. Women who had not lived permanently in the sampled study area for at least 1 year were excluded from the study.

\section{Sample size and sampling}

The minimum sample size required for this study was computed using the sample size estimation formula for single population proportions with the assumptions of: $87 \%$ of women who have at least one antenatal care visit have a non-institutional delivery (further analysis of the 2011 Ethiopian Demographic and Health Survey data was made to get this figure), $95 \%$ confidence level, $2 \%$ margin of error, a design effect of 2 and $10 \%$ compensation for possible non-response. The sample size required for the study was calculated to be 2390 .

The study employed multistage cluster sampling technique to identify the study respondents. Considering the cultural and ethnic diversity of the region (SNNPR), the total sample was allocated proportionately to all administrative subregions (administrative zones, the city administration and special woredas) referring to their respective number of expected deliveries in the year 2012. Next, 76 districts were randomly selected from the administrative subregions; 1 district was chosen for every 55 women participants in the same administrative zone, on average, until the sample for a specific administrative zone is met. Following the selection of districts, all health centres situated in the districts were classified into two categories as close to or distant from the districts' administrative hub. Next, one health centre from each of the close and distant health centres were selected to accommodate the sample allocated for their respective district. A similar fashion was also used to select two health posts under the catchment of the selected health centres. In most of the scenarios, there are five health posts under the catchments of a health centre. Finally, women who delivered 
in the past 1 year preceding the survey time were systematically selected from the catchments of selected health posts using information from family folder registries that exist at the health posts of the selected kebeles.

\section{Variables}

The dependent variable of the study was place of delivery dichotomised as 'institutional' and 'non-institutional'. Women who delivered in health facilities staffed with skilled birth attendants (minimum of nurses) were considered to have had institutional delivery. The explanatory variables were women's sociodemographic characteristics, obstetric characteristics, knowledge and perception on maternal health services and their utilisation, autonomy in decision making, and health facility related factors including distance. To accommodate for the cultural and contextual differences across the different administrative subregions, three-level administrative hierarchy factors (zones, districts and kebeles) were included in the independent variables.

\section{Data collection and processing}

Data were collected by 24 trained data collectors and 6 supervisors in the community, organised in six teams. Data collectors and supervisors received 2 days training on the data collection tool by the principal investigator and two co-investigators. The interviewer administered tool was initially prepared in English and later translated to Amharic, the official working language in the region. The data collectors recorded women's responses to closedended questions. A total of 34 questions were included in the questionnaire. Administration of the interview questionnaire to participant women took $15-20 \mathrm{~min}$ on average. The data collection tool was pretested on $5 \%$ of the total sample size in Dale district, Sidama zone. Further revision of the questionnaire was made to improve its clarity and simplicity.

Quality of the collected data was monitored on a daily basis by the field supervisors who were responsible for assessing the completeness and coherence of every questionnaire. Furthermore, three of the study investigators were responsible for overseeing the quality of the data collected across the entire data collection period.

Data were entered into EpiInfo V.3.4.2 software by expert data entry clerks of the College of Medicine and Health Sciences, Hawassa University. Randomly picked questionnaires were compared with the corresponding entered data for quality control purposes by the principal investigator. Later data were exported to STATA V.14 software for cleaning and analysis purpose by the principal investigator. Frequency distribution, measures of central tendency and dispersion were done to describe essential variables of the study. Furthermore, a mixed-effects logistic regression analysis with random intercepts for zones, districts and kebeles was performed to identify factors related to place of delivery. Initially, bivariate multilevel logistic regression analysis was done to select variables to be included in the multivariate multilevel logistic regression analysis; variables that showed $\mathrm{p}$ value $<0.25$ in the bivariate analysis were included in the multivariate analysis. The absence of multicollinearity between the independent variables was also checked. Participants' marital status and decision making on household financial expenditure were the only two variables not to be included in the multivariate analysis. ORs with their respective $95 \%$ CIs were used as a measure of association between the dependent and independent variables.

\section{Patient involvement}

This study involved only women who had given birth in the year preceding the survey period. The women were not involved in setting the research question, the outcome measures, the design of the study, and the recruitment of study participants. The findings of this study will not be directly disseminated to study participants.

\section{RESULTS}

\section{Sociodemographic characteristics}

From the total 2390 potential respondents initially approached, 2225 respondents were available and willing to participate in the survey, making the response rate $93.1 \%$. The median \pm IQR for age of the respondents was $26 \pm 7$ years and more than half of the participants $(56.5 \%)$ were in the 25-34 years age group. With regard to religion, $60.1 \%$ of participants were protestant Christians. In addition, almost all $(98.0 \%)$ participants were married; more than half (56.8\%) had formal education; $67.6 \%$ were housewives and $21.4 \%$ had an estimated monthly income of $>1044$ Ethiopian birr (US\$57.3 equivalent). Close to half $(46.6 \%)$ of the participants' male partners were reported to have attended grade 1-8, while $22.2 \%$ did not attend formal education at all. Pertaining to household family size, it was reported to be five and above in $62.8 \%$ of the families, median $\pm \mathrm{IQR}=5 \pm 3$ (table 1 ).

\section{Obstetric and reproductive health characteristics}

Early marriage (marriage before the age of 18 years) was $37.2 \%$ in the current study, mean $\pm \mathrm{SD}=18 \pm 3$ years. The mean age at first pregnancy was $19 \pm 3$ years; more than half $(55.0 \%)$ of the participants got pregnant before 20 years of age for the first time. In addition, $43 \%$ of participants had ever been pregnant four or more times prior to the survey. One-fifth (20.2\%) of the participants reported that their last pregnancy was unplanned. With regard to care during pregnancy, $43.8 \%$ of participants had three or less antenatal visits during their index pregnancy. Furthermore, $14.2 \%$ of participants had experienced at least one pregnancy-related health problem during their index pregnancy (table 2).

Access to health facilities and decision making on key events Using the most accessible mode of transport, health posts were the closest health facilities to $68.1 \%$ of the respondents, while hospitals and health centres were close to $4.2 \%$ and $26.7 \%$ of respondents, respectively. With regard 
Table 1 Sociodemographic characteristics of respondents, SNNPR, 2013

\begin{tabular}{|c|c|}
\hline Characteristics & Frequency (\%) \\
\hline \multicolumn{2}{|l|}{ Age in completed years } \\
\hline $15-24$ & $652(29.3)$ \\
\hline $25-34$ & $1257(56.5)$ \\
\hline$\geq 35$ & $316(14.2)$ \\
\hline Total (n) & $2225(100.0)$ \\
\hline \multicolumn{2}{|l|}{ Median \pm IQR $=26 \pm 7$} \\
\hline Total (n) & $2225(100.0)$ \\
\hline \multicolumn{2}{|l|}{ Religion } \\
\hline Orthodox & $469(21.1)$ \\
\hline Protestant & $1338(60.1)$ \\
\hline Muslim & $310(13.9)$ \\
\hline Catholic & $45(2.0)$ \\
\hline Others & $63(2.8)$ \\
\hline Total (n) & $2225(100.0)$ \\
\hline \multicolumn{2}{|l|}{ Marital status } \\
\hline Single & $27(1.2)$ \\
\hline Married & $2180(98.0)$ \\
\hline Divorced & $6(0.3)$ \\
\hline Widowed & $12(0.5)$ \\
\hline Total (n) & $2225(100.0)$ \\
\hline \multicolumn{2}{|c|}{ Educational status of woman } \\
\hline No education & $963(43.3)$ \\
\hline Grade 1-8 & $878(39.5)$ \\
\hline Grade 9 and above & $384(17.3)$ \\
\hline Total (n) & $2225(100.0)$ \\
\hline
\end{tabular}

Educational status of male partners of currently married women

\begin{tabular}{lc} 
No education & $484(22.2)$ \\
\hline Grade 1-8 & $1016(46.6)$ \\
Grade 9 and above & $680(31.2)$ \\
\hline Total (n) & $\mathbf{2 1 8 0 ( 1 0 0 . 0 )}$ \\
Occupation & \\
Farmer & $327(14.7)$ \\
Pastoralist & $40(1.8)$ \\
\hline Merchant & $183(8.2)$ \\
Government employee & $128(5.8)$ \\
Housewife & $1503(67.6)$ \\
Student & $22(1.0)$ \\
Others & $22(1.0)$ \\
\hline Total (n) & $\mathbf{2 2 2 5 ( 1 0 0 . 0 )}$
\end{tabular}

Estimated regular monthly income (in Ethiopian birr)

\begin{tabular}{|c|c|}
\hline$<1045$ & $1713(78.2)$ \\
\hline$\geq 1045$ & 477 (21.4) \\
\hline Total (n) & $2190(100.0)$ \\
\hline
\end{tabular}

\begin{tabular}{lc} 
Table 1 Continued & Frequency (\%) \\
\hline Characteristics & \\
\hline \multicolumn{1}{l}{ Median $\pm \mid \mathrm{QR}=500 \pm 800$} & \\
Household family size & \\
$\leq 4$ & $828(37.2)$ \\
$\geq 5$ & $1397(62.8)$ \\
Total (n) & $2225(\mathbf{1 0 0 . 0 )}$ \\
Median $\pm \mid \mathrm{QR}=5 \pm 3$ & \\
\hline
\end{tabular}

SNNPR, Southern Nations Nationalities and Peoples Region.

to the women respondents' household financial management, $38.7 \%$ of them reported that they make joint decisions with their male partner; $53.6 \%$ of respondents reported that household financial expenditure decisions

Table 2 Obstetric and reproductive health characteristics of respondents, SNNPR, 2013

\begin{tabular}{|c|c|}
\hline Characteristics & Frequency $(\%)$ \\
\hline \multicolumn{2}{|c|}{ Age at first marriage (in years) } \\
\hline$<18$ & $816(37.2)$ \\
\hline$\geq 18$ & $1379(62.8)$ \\
\hline Total (n) & $2195(100.0)$ \\
\hline \multicolumn{2}{|c|}{ Mean $\pm \mathrm{SD}=18 \pm 3$} \\
\hline \multicolumn{2}{|c|}{ Age at first pregnancy (in years) } \\
\hline$<20$ & $1220(55.0)$ \\
\hline$\geq 20$ & $1000(45.0)$ \\
\hline Total (n) & $2220(100.0)$ \\
\hline \multicolumn{2}{|c|}{ Mean $\pm S D=19 \pm 3$} \\
\hline \multicolumn{2}{|c|}{ Number of total pregnancy/ies } \\
\hline$\leq 3$ & $1269(57.0)$ \\
\hline$\geq 4$ & $956(43.0)$ \\
\hline Total (n) & $2225(100.0)$ \\
\hline \multicolumn{2}{|l|}{ Mean $\pm S D=3 \pm 3$} \\
\hline \multicolumn{2}{|c|}{ Was the index pregnancy planned? } \\
\hline Yes & $1775(79.8 \%)$ \\
\hline No & $450(20.2)$ \\
\hline Total & $2225(100.0)$ \\
\hline
\end{tabular}

Number of antenatal visits for the index pregnancy

$\begin{array}{lc}\leq 3 & 974(43.8) \\ \geq 4 & 1251(56.2) \\ \text { Total (n) } & 2225(\mathbf{1 0 0 . 0 )}\end{array}$

Experienced any health problem during index pregnancy

\begin{tabular}{lc} 
Yes & $317(14.2)$ \\
No & $1883(84.6)$ \\
Do not remember & $25(1.1)$ \\
Total (n) & $\mathbf{2 2 2 5}(\mathbf{1 0 0 . 0 )}$ \\
\hline
\end{tabular}

SNNPR, Southern Nations Nationalities and Peoples Region. 
Table 3 Access to health facilities and household decision making on key events, SNNPR, 2013

\begin{tabular}{|c|c|}
\hline Characteristics & Frequency $(\%)$ \\
\hline \multicolumn{2}{|c|}{$\begin{array}{l}\text { Closest health facility using the most accessible transpor } \\
\text { method }\end{array}$} \\
\hline Hospital & $94(4.2)$ \\
\hline Health centre & $595(26.7)$ \\
\hline Higher clinic & $21(0.9)$ \\
\hline Health post & $1515(68.1)$ \\
\hline Total & $2225(100.0)$ \\
\hline \multicolumn{2}{|c|}{ Decision maker on household financial expenditure } \\
\hline Woman and her male partner & $861(38.7)$ \\
\hline Woman respondent & $154(6.9)$ \\
\hline Male partner & $1193(53.6)$ \\
\hline Woman's close relative & $13(0.6)$ \\
\hline Others & $4(0.2)$ \\
\hline Total (n) & $2225(100.0)$ \\
\hline \multicolumn{2}{|c|}{ Decision maker on healthcare service utilisation } \\
\hline Woman and her male partner & $715(32.1)$ \\
\hline Woman respondent & $788(35.4)$ \\
\hline Male partner & $699(31.4)$ \\
\hline Woman's close relative & $5(0.2)$ \\
\hline Others & $18(0.8)$ \\
\hline Total (n) & $2225(100.0)$ \\
\hline \multicolumn{2}{|c|}{ Decision maker on place of delivery } \\
\hline Woman and her male partner & $705(31.7)$ \\
\hline Woman respondent & $934(42.0)$ \\
\hline Male partner & $516(23.2)$ \\
\hline Woman's close relative & $8(0.4)$ \\
\hline Others & $62(2.8)$ \\
\hline Total (n) & $2225(100.0)$ \\
\hline
\end{tabular}

SNNPR, Southern Nations Nationalities and Peoples Region.

are taken by their male partner alone. Furthermore, decisions on healthcare services utilisation was reported to be usually made by male partner alone by $31.4 \%$ of respondents; $35.4 \%$ of women reported that they independently make decisions on their own healthcare services utilisation. Joint decisions (by respondents and respective male partners) on the place of childbirth was reported by $31.7 \%$ of the respondents; $42 \%$ of respondents make decision on their place of delivery alone (table 3 ).

Knowledge, perception and experience of danger signs during pregnancy and childbirth

Less than half $(43.0 \%)$ of the respondents know danger sign/s that may occur during pregnancy; the most commonly reported danger sign was bleeding from the uterus $(57.2 \%)$ followed by severe headache $(35.6 \%)$ and severe abdominal pain (33.9\%) (table 4). Similarly, $58.5 \%$ of respondents knew danger sign/s that may occur
Table 4 Knowledge and perception of danger signs and place of delivery, SNNPR, 2013

\section{Characteristics}

Frequency (\%)

Do you know any danger sign/s of pregnancy?

\begin{tabular}{|c|c|}
\hline Yes & $956(43.0)$ \\
\hline No & 1269 (57.0) \\
\hline Total (n) & $2225(100.0)$ \\
\hline
\end{tabular}

Risks mentioned by respondents* $(n=956)$

$\begin{array}{lc}\text { Swelling of the leg or face } & 306(32.0) \\ \text { Bleeding from the uterus } & 547(57.2) \\ \begin{array}{l}\text { Foul smelling discharge from the } \\ \text { uterus }\end{array} & 51(5.3)\end{array}$

$\begin{array}{lc}\text { Absence of fetal movement } & 140(14.6) \\ \text { Severe abdominal pain } & 324(33.9) \\ \text { Severe headache } & 340(35.6) \\ \text { Difficult breathing } & 119(12.4) \\ \text { Leak of water } & 82(8.6) \\ \text { Fever } & 143(15.0) \\ \text { Blurring of vision } & 218(22.8)\end{array}$

Do you know any danger sign/s of childbirth?

\begin{tabular}{lc} 
Yes & $1301(58.5)$ \\
No & $924(41.50)$ \\
\hline Total $(\mathbf{n})$ & $2225(\mathbf{1 0 0 . 0})$ \\
Risks mentioned by respondents ${ }^{*}(\mathrm{n}=1301)$ \\
\hline Too long labour & $933(71.70)$ \\
Excessive bleeding & $801(61.6)$ \\
Early breakage of water & $256(19.7)$ \\
Retained placenta & $547(24.6)$ \\
Convulsion & $324(33.9)$ \\
High blood pressure & $96(7.4)$ \\
Cessation of labour pain & $80(6.1)$
\end{tabular}

Respondent experienced any of these danger sign/s during childbirth

$\begin{array}{ll}\text { Yes } & 307(32.1) \\ \text { No } & 645(67.5) \\ \text { Total (n) } & 952 \text { (100.0) }\end{array}$

Respondent perceives giving birth at home pose risk/s

$\begin{array}{lc}\text { Yes } & 1599(71.9) \\ \text { No } & 626(28.1) \\ \text { Total (n) } & \mathbf{2 2 2 5 ( 1 0 0 . 0 )}\end{array}$

Respondent perceives most complications during childbirth are preventable

$\begin{array}{lc}\text { Yes } & 1523(68.4) \\ \text { No } & 702(31.6) \\ \text { Total (n) } & \mathbf{2 2 2 5 ( 1 0 0 . 0 )}\end{array}$

Respondent perceives oneself susceptible to complication/s during childbirth
Yes
$1672(75.1)$ 


\begin{tabular}{|c|c|}
\hline Characteristics & Frequency (\%) \\
\hline No & $553(24.9)$ \\
\hline Total (n) & $2225(100.0)$ \\
\hline \multicolumn{2}{|l|}{ Place of delivery of the index pregnancy } \\
\hline Non-institutional & $1384(62.2 \%)$ \\
\hline Institutional & $841(37.8 \%)$ \\
\hline Total & $2225(100.0)$ \\
\hline \multicolumn{2}{|c|}{ Reason/s for non-institutional delivery* $(n=1384)$} \\
\hline Previous short and simple labour & $649(46.9)$ \\
\hline $\begin{array}{l}\text { I had previous uncomplicated home } \\
\text { delivery }\end{array}$ & $593(42.9)$ \\
\hline Night-time labour & $411(29.7)$ \\
\hline $\begin{array}{l}\text { I had no problem during my } \\
\text { pregnancy }\end{array}$ & $260(18.8)$ \\
\hline Perceived providers poor reception & $247(17.8)$ \\
\hline Transport problem & $76(5.5)$ \\
\hline Health facility is far & $65(4.7)$ \\
\hline Fear of exposing private area & $51(3.7)$ \\
\hline Prefer traditional birth attendants & $51(3.7)$ \\
\hline Male partner did not allow & $32(2.3)$ \\
\hline Fear of male birth attendants & $20(1.5)$ \\
\hline
\end{tabular}

*More than one response possible.

SNNPR, Southern Nations Nationalities and Peoples Region.

during childbirth; long labour was the most frequently reported danger sign $(71.7 \%)$, followed by excessive bleeding $(61.6 \%)$ and convulsions $(33.9 \%)$ (table 4 ). About one-third $(32.1 \%)$ of respondents reported that they had experienced at least one of these danger sign/s during their childbirth. From the total respondents, $75.1 \%$ perceived themselves to be susceptible to complications during childbirth; $68.4 \%$ of respondents believed that childbirth complications are preventable. In addition, $71.9 \%$ of respondents knew that giving birth at home poses a risk (table 4$)$.

\section{Place of delivery}

The proportion of non-institutional deliveries among the respondents was $62.2 \%$ (95\% CI $60.2 \%$ to $64.2 \%$ ), while the remaining delivered in health institutions. Among the reasons for non-institutional delivery, previous experience of short and simple labour (46.9\%), previous experience of uncomplicated home birth $(42.9 \%)$, night-time labour (29.7\%), no pregnancy-related problem while pregnant $(18.8 \%)$, and transportation problem $(5.5 \%)$ were the major ones (table 4 ). In addition, $17.8 \%$ of respondents reported providers' poor reception of women as a reason to avoid institutional delivery.

\section{Predictors of non-institutional delivery}

The multivariable mixed-effects logistic regression analyses revealed that attending secondary school and above
( $\mathrm{AOR}=0.51 ; 95 \% \mathrm{CI} 0.30$ to 0.85$)$, having a male partner who attended secondary school or above (AOR $=0.58 ; 95 \%$ CI 0.37 to 0.92$)$, being a government employee $(\mathrm{AOR}=0.27$; $95 \% \mathrm{CI} 0.10$ to 0.78 ), and 20 or more years of age at first pregnancy (AOR $=0.70 ; 95 \%$ CI 0.49 to 0.99 ) were the sociodemographic features negatively associated with non-institutional delivery. Participants whose index pregnancy was unplanned (AOR=1.67; 95\% CI 1.16 to 2.42) and who did not experience any health problem during their pregnancy ( $\mathrm{AOR}=8.1 ; 95 \%$ CI 3.12 to 24.62) were more likely to have non-institutional delivery. In addition, women who reside closer to health posts were more likely to have non-institutional delivery than those who reside closer to hospitals (AOR=9.07; 95\% CI 3.74 to 21.99) (table 5).

With regard to household decision making, the odds of non-institutional delivery was less among women who make independent decisions on healthcare service utilisation than those who make joint decisions with their male partners (AOR $=0.51 ; 95 \%$ CI 0.33 to 0.79 ). However, no significant difference on place of delivery was observed with regard to women's decision-making scope on household financial expenditure and the choice of place of delivery. The odds of non-institutional delivery were higher among women who did not perceive any risks associated with home delivery (AOR $=6.64 ; 95 \%$ CI 4.35 to 10.14) (table 6).

\section{DISCUSSION}

Differences in livelihood characteristics, health system performance and cultural beliefs and practices are believed to be associated with maternal health services utilisation in SNNPR. ${ }^{4515}$ Therefore, this study has taken into account the potential clustering of the variation in institutional delivery service utilisation that may exist between the different administrative zones and their subdivisions in south Ethiopia. Previous researches, ${ }^{13} 1617$ a systematic review ${ }^{17}$ and further analyses of the demographic and health survey data ${ }^{518} 19$ all focus on identifying the determinants of institutional delivery, including antenatal visits, among women of reproductive age groups. However, our study investigated predictors of institutional delivery among women who attended antenatal visits.

The proportion of antenatal care attendees who had non-institutional delivery was $62 \%$ in this study. This proportion is less than the proportion $(87 \%)$ reported by the Ethiopian Demographic and Health Survey for the 5 years preceding $2011 .^{2}$ This reduction may be due to implementation of the multidimensional strategies of the health sector development programme that have included rapid expansion of healthcare facilities and training of health workforce, including health extension workers. 52021

Previous experience of simple labour and uncomplicated home delivery were the main reasons for having non-institutional delivery in the current study. A qualitative study from rural catchments of South Wollo, Ethiopia, 
Table 5 Sociodemographic and obstetric predictors of non-institutional delivery, SNNPR, 2013

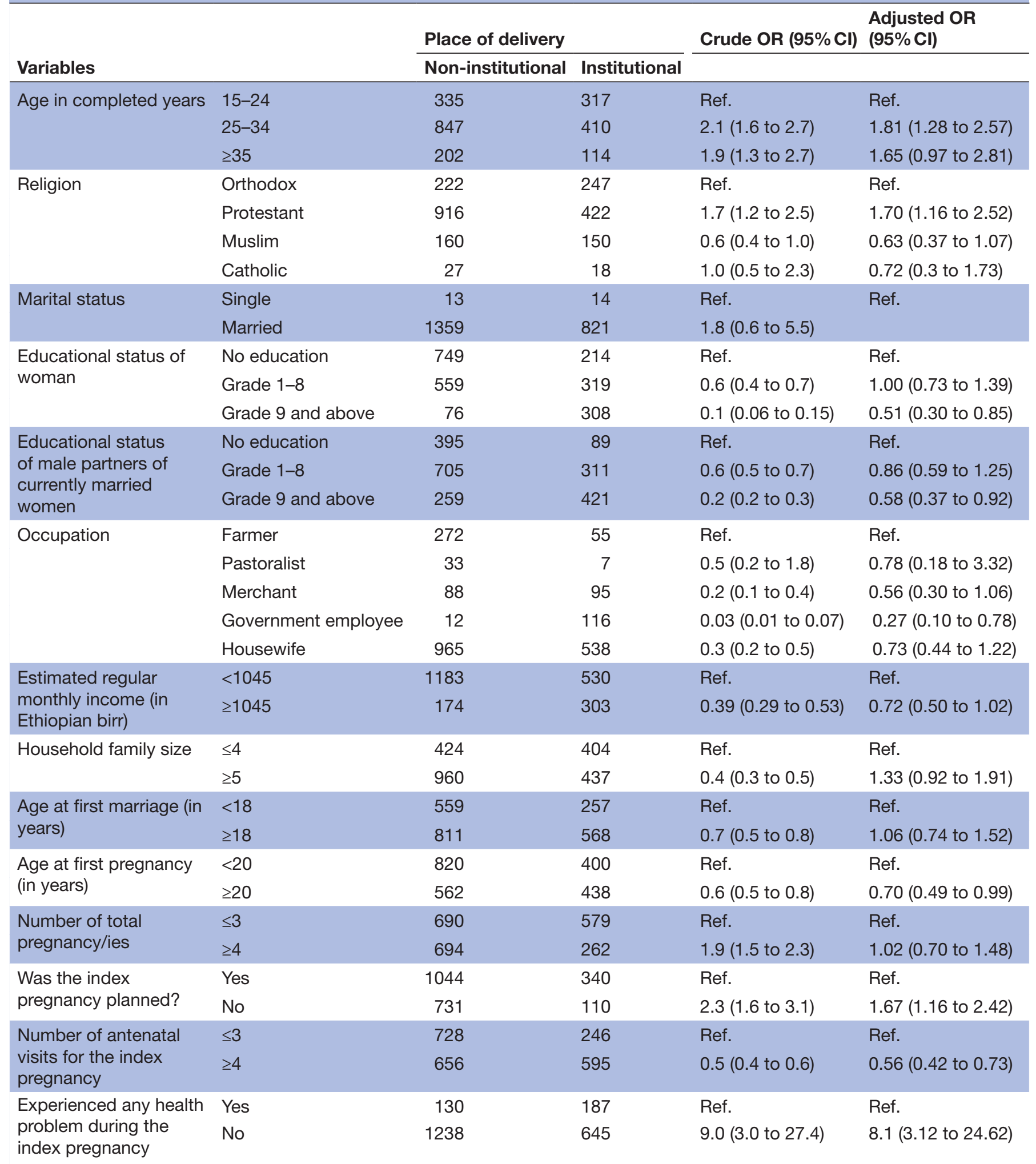

SNNPR, Southern Nations Nationalities and Peoples Region.

reported that women consider a short birth (one that lasts $<4$ hours) that takes place at home surrounded by relatives as a normal delivery that does not necessitate a medical care. ${ }^{22}$ This is also supported by another study from northwest Ethiopia which found that most women sought antenatal (40.8\%) and skilled delivery $(45.3 \%)$ care because of illness only. ${ }^{6}$ In addition, non-institutional delivery was 10-fold higher among women who did 
Table 6 Access, decision making, knowledge and perception-related predictors of non-institutional delivery, SNNPR, 2013

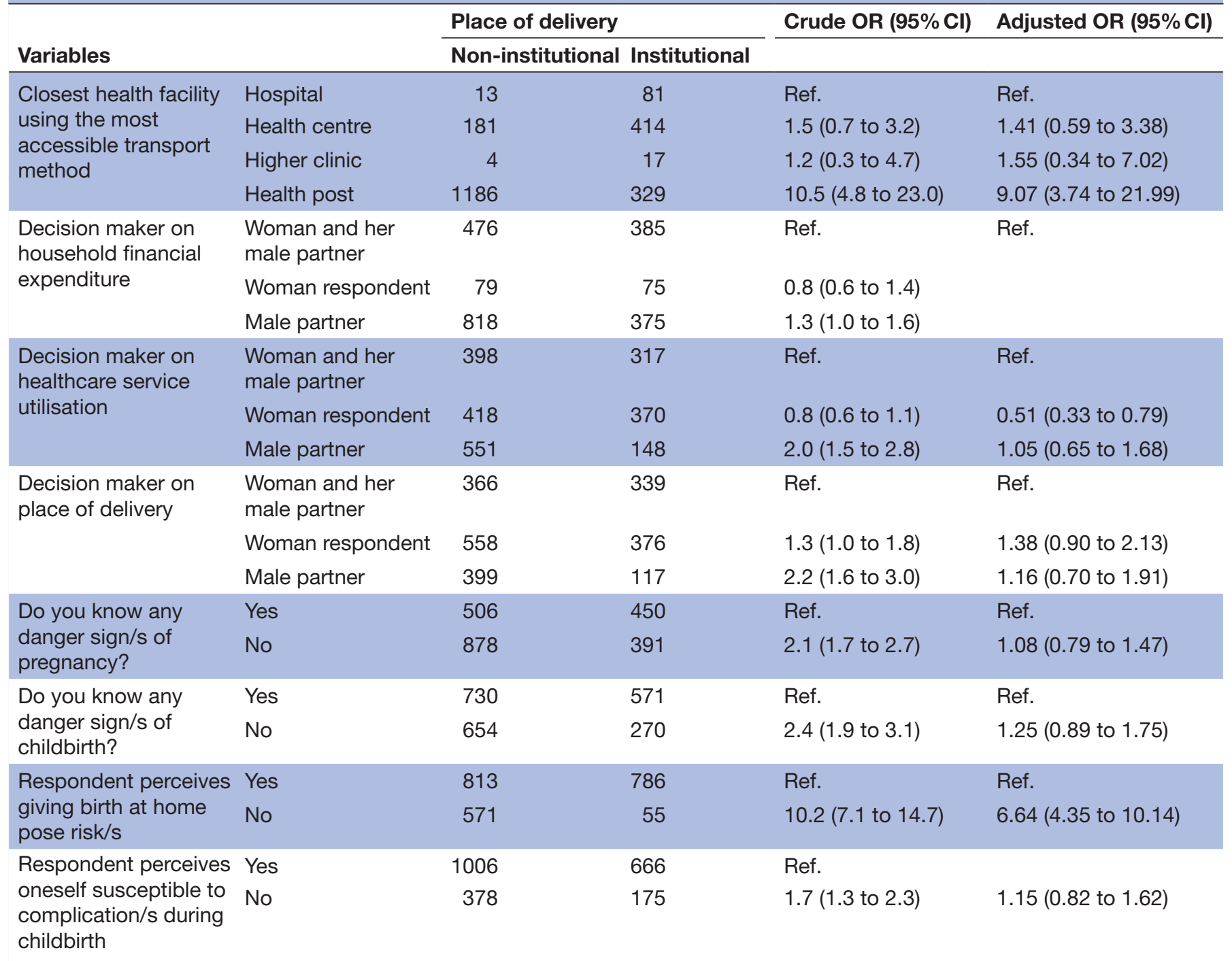

SNNPR, Southern Nations Nationalities and Peoples Region.

not recognise the risks associated with home delivery. A similar scenario was also evident in a study conducted in three sub-Saharan African countries (Kenya, Nigeria and Tanzania) and three South Asian countries (Bangladesh, India and Pakistan). ${ }^{15}$

Fear of poor reception by health service providers during facility-based childbirth was reported as a reason for avoiding institutional delivery by $17.8 \%$ of participants of the current study. Ethiopian health service providers have also witnessed the hostile way some health service providers treat women during facility-based childbirth, which discourages women and their neighbourhoods from attending health facilities in the future. ${ }^{11}$ Discrete choice experiments among women in Tanzania and southwest Ethiopia also revealed that the health service providers' attitudes are one of the most important attributes women consider when deciding whether to have an institutional delivery. ${ }^{23} 24$
In the current study, non-institutional delivery was less common among participants who make independent decisions on general health services utilisation. A secondary review from Ethiopia also revealed that women who make autonomous decisions on healthcare spending have lower odds of delivering outside health institutions. ${ }^{18}$ The same scenario is true in a neighbouring Eritrea, ${ }^{25}$ Ghana ${ }^{26}$ and Bangladesh. ${ }^{27}$ In addition, a study from Jimma, south-western Ethiopia, revealed that autonomous decision making was a strong predictor of place of delivery among antenatal care attendees. ${ }^{28}$

As depicted by this study and a study from northern Ethiopia $^{29}$ and Nigeria, ${ }^{30}$ drop out of women from the continuum of care, which runs from antenatal through to postnatal care, is a missed opportunity in the efforts to reduce maternal mortality. However, there are field-tested proven interventions to improve the quality of maternity care services, thereby mitigating drop out in Ethiopia and other low-income settings. ${ }^{31-34}$ 
This community-based study is different from other studies conducted in Ethiopia because it sampled women who had attended at least one antenatal visit. Furthermore, the study covered all administrative levels in SNNPR which are home to 56 nations and nationalities and thus accounted for possible cultural diversities and variations in residential settings (urban, rural agrarian and rural pastoralist). This study would have benefited more from exploration of women's experiences of antenatal care that are believed to highly influence their decision on place of delivery. We recommend future similar studies include qualitative enquiry among antenatal care attendees to deepen understanding of causes of dropouts from the continuum of maternal health services rendered in Ethiopian health facilities.

\section{CONCLUSIONS}

This study has revealed that almost two-thirds of women who had antenatal visits delivered at home. This highlights a major missed opportunity to retain women in the continuum of maternal healthcare in southern Ethiopia. Further health system innovations that help to bridge the gap between antenatal care attendance and institutional delivery are highly recommended to improve the health of Ethiopian women and reduce maternal mortality from preventable causes.

Acknowledgements The authors would like to thank the study participants and data collectors for their active role in the data collection activities. The authors would also like to thank staff of the research and technology transfer support process at the SNNPR Health Bureau for their cooperation and assistance during the conduct of this study.

Contributors AAs and TM conceived the study; AAs, AM and MK conducted a thorough literature review; AAs and TM designed the study and developed data collection tools; AAs, TM and YL trained data collectors and supervised data collection; AAs and SG analysed the data; AAs, TM, YL, ES and AAl prepared and reviewed comprehensive report of the study; AAs drafted the manuscript. All authors made critical review of the manuscript. All authors read and approved the final manuscript.

Funding This work was supported by the Save the Children International, Ethiopia country office.

Disclaimer The funder had no role in the design, fieldwork, analysis and interpretation of the findings.

Competing interests None declared.

Patient consent for publication Not required.

Ethics approval This study received an ethical approval from the Institutional Review Board located in SNNPR Health Bureau, Ethiopia. Additionally, permission letter was granted from SNNPR Health Bureau. Written consent was given by all women who participated in the study. Literate women were given an information sheet to read and a consent form to sign on. For illiterate women, the information sheet and the summaries on the consent form were read by the data collectors and participants' finger prints were collected on the consent sheets.

Provenance and peer review Not commissioned; externally peer reviewed.

Data sharing statement Reasonable requests can be made to access data of this study from the primary author.

Open access This is an open access article distributed in accordance with the Creative Commons Attribution Non Commercial (CC BY-NC 4.0) license, which permits others to distribute, remix, adapt, build upon this work non-commercially, and license their derivative works on different terms, provided the original work is properly cited, appropriate credit is given, any changes made indicated, and the use is non-commercial. See: http://creativecommons.org/licenses/by-nc/4.0/.
REFERENCES

1. World Health Organization. Trends in maternal mortality: 1990 to 2015: estimates by WHO, UNICEF, UNFPA, World Bank Group and the United Nations Population Division. Geneva, Switzerland: World Health Organization, 2015.

2. Central Statistical Agency (CSA) [Ethiopia] and ICF. Ethiopia Demographic and Health Survey 2016: Key Indicators Report. Addis Ababa, Ethiopia, and Rockville, Maryland, USA: CSA and ICF, 2016.

3. Alvarez JL, Gil R, Hernández V, et al. Factors associated with maternal mortality in Sub-Saharan Africa: an ecological study. BMC Public Health 2009;9:462.

4. Alam N, Hajizadeh M, Dumont A, et al. Inequalities in maternal health care utilization in sub-Saharan African countries: a multiyear and multi-country analysis. PLoS One 2015;10:e0120922.

5. Memirie ST, Verguet S, Norheim OF, et al. Inequalities in utilization of maternal and child health services in Ethiopia: the role of primary health care. BMC Health Serv Res 2016;16:51.

6. Kebede B, Gebeyehu A, Andargie G. Use of previous maternal health services has a limited role in reattendance for skilled institutional delivery: cross-sectional survey in Northwest Ethiopia. Int $J$ Womens Health 2013;5:79-85.

7. King R, Jackson R, Dietsch E, et al. Barriers and facilitators to accessing skilled birth attendants in Afar region, Ethiopia. Midwifery 2015;31:540-6.

8. Wilunda C, Quaglio G, Putoto G, et al. Determinants of utilisation of antenatal care and skilled birth attendant at delivery in South West Shoa Zone, Ethiopia: a cross sectional study. Reprod Health 2015;12:74.

9. Alemayehu M, Mekonnen W. The Prevalence of Skilled Birth Attendant Utilization and Its Correlates in North West Ethiopia. Biomed Res Int 2015;2015:1-8.

10. Hailu $D$, Berhe H. Determinants of institutional childbirth service utilisation among women of childbearing age in urban and rural areas of Tsegedie district, Ethiopia. Midwifery 2014;30:1109-17.

11. Sipsma H, Thompson J, Maurer L, et al. Preferences for home delivery in Ethiopia: provider perspectives. Glob Public Health 2013;8:1014-26.

12. Mirkuzie AH. Exploring inequities in skilled care at birth among migrant population in a metropolitan city Addis Ababa, Ethiopia; a qualitative study. Int J Equity Health 2014;13:110.

13. Roro MA, Hassen EM, Lemma AM, et al. Why do women not deliver in health facilities: a qualitative study of the community perspectives in south central Ethiopia? BMC Res Notes 2014;7:556.

14. Coast E, Jones E, Portela A, et al. Maternity care services and culture: a systematic global mapping of interventions. PLoS One 2014;9:e108130.

15. Tey NP, Lai SL. Correlates of and barriers to the utilization of health services for delivery in South Asia and Sub-Saharan Africa. ScientificWorldJournal 2013;2013:1-11.

16. Shiferaw S, Spigt M, Godefrooij M, et al. Why do women prefer home births in Ethiopia? BMC Pregnancy Childbirth 2013;13:5.

17. Kebede A, Hassen K, Nigussie Teklehaymanot A. Factors associated with institutional delivery service utilization in Ethiopia. Int $J$ Womens Health 2016;8:463-75.

18. Tarekegn SM, Lieberman LS, Giedraitis V. Determinants of materna health service utilization in Ethiopia: analysis of the 2011 Ethiopian Demographic and Health Survey. BMC Pregnancy Childbirth 2014;14:161.

19. Yebyo $\mathrm{H}$, Alemayehu M, Kahsay A. Why do women deliver at home? Multilevel modeling of Ethiopian National Demographic and Health Survey data. PLoS One 2015;10:e0124718.

20. Sibley LM, Tesfaye S, Fekadu Desta B, et al. Improving maternal and newborn health care delivery in rural Amhara and Oromiya regions of Ethiopia through the Maternal and Newborn Health in Ethiopia Partnership. J Midwifery Womens Health 2014;59(Suppl 1):S6-20.

21. The Federal Democratic Republic of Ethiopia Ministry of Health. Health Sector Transformation Plan: 2015/16 - 2019/20. Addis Ababa, Ethiopia: Federal Ministry of Health, 2015.

22. Bedford J, Gandhi M, Admassu M, et al. 'A normal delivery takes place at home': a qualitative study of the location of childbirth in rural Ethiopia. Matern Child Health J 2013;17:230-9.

23. Kruk ME, Paczkowski M, Mbaruku G, et al. Women's preferences for place of delivery in rural Tanzania: a population-based discrete choice experiment. Am J Public Health 2009;99:1666-72.

24. Kruk ME, Paczkowski MM, Tegegn A, et al. Women's preferences for obstetric care in rural Ethiopia: a population-based discrete choice experiment in a region with low rates of facility delivery. $J$ Epidemiol Community Health 2010;64:984-8.

25. Woldemicael G, Tenkorang EY. Women's autonomy and maternal health-seeking behavior in Ethiopia. Matern Child Health $\mathrm{J}$ 2010;14:988-98. 
26. Speizer IS, Story WT, Singh K. Factors associated with institutional delivery in Ghana: the role of decision-making autonomy and community norms. BMC Pregnancy Childbirth 2014;14:398.

27. Haider MR, Qureshi ZP, Khan MM. Effects of women's autonomy on maternal healthcare utilization in Bangladesh: Evidence from a national survey. Sex Reprod Healthc 2017;14:40-7.

28. Dida N, Birhanu Z, Gerbaba M, et al. Modeling the probability of giving birth at health institutions among pregnant women attending antenatal care in West Shewa Zone, Oromia, Ethiopia: a cross sectional study. Afr Health Sci 2014;14:288-98.

29. Bayu H, Adefris M, Amano A, et al. Pregnant women's preference and factors associated with institutional delivery service utilization in Debra Markos Town, North West Ethiopia: a community based follow up study. BMC Pregnancy Childbirth 2015;15:15.
30. Akinyemi JO, Afolabi RF, Awolude OA. Patterns and determinants of dropout from maternity care continuum in Nigeria. BMC Pregnancy Childbirth 2016;16:282.

31. Elmusharaf K, Byrne E, O'Donovan D. Strategies to increase demand for maternal health services in resource-limited settings: challenges to be addressed. BMC Public Health 2015;15:870.

32. Lindtjørn B, Mitiku D, Zidda Z, et al. Reducing Maternal Deaths in Ethiopia: Results of an Intervention Programme in Southwest Ethiopia. PLoS One 2017;12:e0169304.

33. Metcalfe R, Adegoke AA. Strategies to increase facility-based skilled birth attendance in South Asia: a literature review. Int Health 2013;5:96-105.

34. World Health Organization. Strategies toward ending preventable maternal mortality (EPMM): World Health Organization, 2015. 